\title{
Mechanisms of Risk and Resilience in Military Families: Theoretical and Empirical Basis of a Family-Focused Resilience Enhancement Program
}

\author{
William R. Saltzman • Patricia Lester • \\ William R. Beardslee · Christopher M. Layne • \\ Kirsten Woodward • William P. Nash
}

Published online: 8 June 2011

(c) The Author(s) 2011. This article is published with open access at Springerlink.com

\begin{abstract}
Recent studies have confirmed that repeated wartime deployment of a parent exacts a toll on military children and families and that the quality and functionality of familial relations is linked to force preservation and readiness. As a result, family-centered care has increasingly become a priority across the military health system. FOCUS (Families OverComing Under Stress), a familycentered, resilience-enhancing program developed by a team at UCLA and Harvard Schools of Medicine, is a primary initiative in this movement. In a large-scale implementation project initiated by the Bureau of Navy Medicine, FOCUS has been delivered to thousands of Navy, Marine, Navy Special Warfare, Army, and Air Force families since 2008. This article describes the theoretical
\end{abstract}

W. R. Saltzman $(\bowtie)$

UCLA Semel Institute for Neuroscience and Human Behavior and California State University, Long Beach, CA, USA

e-mail:wrsaltzman@mednet.ucla.edu

P. Lester

UCLA Semel Institute for Neuroscience and Human Behavior,

Los Angeles, CA, USA

W. R. Beardslee

Children's Hospital Boston, Harvard Medical School,

Boston, MA, USA

C. M. Layne

UCLA/Duke National Center for Child Traumatic Stress,

Los Angeles, CA, USA

K. Woodward

United States Bureau of Navy Medicine and Surgery,

Washington, DC, USA

W. P. Nash

Defense Centers of Excellence for Psychological Health

and TBI, Silver Spring, MD, USA and empirical foundation and rationale for FOCUS, which is rooted in a broad conception of family resilience. We review the literature on family resilience, noting that an important next step in building a clinically useful theory of family resilience is to move beyond developing broad "shopping lists" of risk indicators by proposing specific mechanisms of risk and resilience. Based on the literature, we propose five primary risk mechanisms for military families and common negative "chain reaction" pathways through which they undermine the resilience of families contending with wartime deployments and parental injury. In addition, we propose specific mechanisms that mobilize and enhance resilience in military families and that comprise central features of the FOCUS Program. We describe these resilience-enhancing mechanisms in detail, followed by a discussion of the ways in which evaluation data from the program's first 2 years of operation supports the proposed model and the specified mechanisms of action.

Keywords Resilience $\cdot$ Family resilience $\cdot$ Military family · FOCUS - FOCUS project · Risk and resilience . Resilience enhancement program - Trauma treatment program - Combat stress program - Wartime deployment . Family stress · Military family treatment - Military child and family $\cdot$ Military family prevention

\section{Introduction}

It is increasingly clear that wartime deployment is a family matter. Almost half of today's active duty forces are parents, and continuing hostilities in Iraq and Afghanistan ensure that growing numbers of military families will experience repeated cycles of separation in a context of danger that may span across years of each family's 
development. Research conducted since the beginning of Operation Enduring Freedom (OEF) in Afghanistan and Operation Iraqi Freedom (OIF) in Iraq point to the strain that wartime deployment places on families, as gauged by a broad range of indicators. These include increased rates of marital conflict and domestic violence (Ruscio et al. 2002), increased risk of parental maltreatment or neglect of children (Gibbs et al. 2007; Rentz et al. 2007), spousal depression, anxiety and "secondary traumatization" that interferes with effective parenting (Galovski and Lyons 2004; Mansfield et al. 2010), and an increased risk for emotional and behavioral problems among military children (Chandra et al. 2011; Flake et al. 2009; Lester et al. 2011b).

To address family-level consequences of wartime deployment, the Department of Defense and the US Navy in particular, has moved toward a preventive and familybased approach to psychological health promotion that reflects the fundamental connection between force readiness and preservation on the one hand, and the quality of relationship and functioning of individual service member's families and primary support networks on the other (Wesphal and Woodward 2010). This evolution has been driven by the growing knowledge base on resilience, both within and outside the military, and by the urgent and pragmatic need to both sustain the psychological health and combat readiness of Sailors, Marines, Soldiers, and Airmen across repeated cycles of deployment, and safeguard the immediate and long-term health and development of military children and families.

The FOCUS (Families OverComing Under Stress) Program plays a primary role within this broader initiative. FOCUS is a strength-based, family-centered resiliency training program developed at the University of California, Los Angeles (UCLA), and Harvard School of Medicine that draws on converging developments within the fields of trauma treatment, prevention science, and developmental psychopathology. The FOCUS Project service program was initiated as a large-scale demonstration project by the Navy Bureau of Medicine and Surgery (BUMED) in March 2008. Since the initiation of this project at 7 USMC and USN sites, the implementation has been expanded to 18 installations serving Marine, Navy Fleet, Navy Seabee, Naval Special Warfare, and Army and Air Force families. To date, FOCUS has provided resiliency training services to approximately 5,000 military children, spouses, and service members through its individual family intervention and over 200,000 family members, providers, and other community members via child and parent skill-building groups and workshops, consultations, and briefings.

This article describes the theoretical and empirical rationale for the design and content of the FOCUS Program. We first trace the progression of conceptions of resilience, giving attention to their evolution from an early focus on individual traits, to models that viewed resilience as primarily a function of relational processes within and outside the family; to current efforts to move beyond identifying numerous indicators of risk and resilience by instead shedding light on underlying causal mechanisms and processes (Luthar 2006). As noted by Rutter (1999), this more precise level of understanding is best suited to guide the development of brief interventions that target key family processes that are demonstrably linked to individual and family resilience. Next, we draw on the literature regarding the impact of wartime deployment and parental distress on family functioning and child adjustment to propose five theorized risk mechanisms. These mechanisms may both serve to describe and explain the specific difficulties that military families experience and provide a broader template for understanding the risk processes that underlie families' adjustment to a broad range of traumatic and other stressful circumstances. We then propose five mechanisms theorized to strengthen family resilience that comprise central intervention components of the FOCUS Program. This is followed by a description of the development of the program, a case example, and a review of program outcomes in light of the proposed model. We conclude by discussing plans and opportunities for further development, application, and study.

\section{Evolution of Models of Resilience}

Resilience is defined as a dynamic process encompassing positive adaptation (and not merely the absence of pathology or dysfunction) within the context of significant adversity (Luthar 2006). The construct of resilience has evolved and garnered great interest by scientists, practitioners, and government agencies over the past three decades due to its far-reaching implications for research, intervention, and public policy. Resilience was initially proposed as a means of explaining why children exposed to similar hardships frequently manifest very different outcomes-some devastated by early trauma and adversity, whereas others emerge intact and at times strengthened (Garmezy 1974). Early studies tended to focus on individual traits presumed to impart "hardiness," giving rise to such conceptions as the "invulnerable child" - a youth considered impervious to stress due to inner fortitude or to such characteristics as high creativity and competence (Anthony 1974; Rutter 1979). Later studies focused on resilient adaptation in diverse settings using longitudinal designs that permitted in-depth analyses of resilience processes over time. Key elaborations of the construct focused on the "locus" of factors presumed to enhance child resilience. These studies underscored both the central 
importance of the family and wider social environment (Garmezy 1987; Werner and Smith 2001), and the understanding that resilience is not simply a "mantle" of fixed attributes, but rather a dynamic process that fluctuates across development in accordance with new challenges, strengths, vulnerabilities, opportunities, and emerging competencies (Garmezy and Masten 1986; Layne et al. 2007).

A landmark study of resilience, initiated by Werner and Smith in 1954, involved the longitudinal investigation of "at risk" infants on the island of Kauai with follow-up assessments continuing to the present day (Werner 1993). Of particular interest, risks associated with poverty were mediated by disruptions in the quality of the caregiving environment, particularly instability and disorganization of the family, while affectional ties within the family and within extrafamilial informal support systems acted as protective factors. In contrast to early individual-based conceptions of resilience, these and other findings highlighted the relational basis of resilience. And though subsequent studies focused primarily on the role of parentchild relationships as the critical element in fostering child resilience (Forgatch and Ogden 2006; Gewirtz et al. 2008), a number of studies have supported a broader systemic appreciation of the ways in which nuclear and extended family members provide opportunities for multiple, dovetailing levels of supportive transactions (Masten et al. 1990; Hauser 1999). These insights suggest that intervention efforts that target only parenting practices or the parent-child relationship may not leverage or sufficiently mobilize the resilience-enhancing potential of the broader family system (Walsh 2006) or recognize the degree to which quality parenting itself is dependent on a host of broader family and contextual factors (Luthar et al. 2001; Brody 2004).

Another important direction in the development of models of resilience has been the movement from focusing simply on broad indicators or predictors of risk and resilience to the clarification of specific mechanisms of action that support or undermine resilient functioning (Layne et al. 2007, 2009; Luthar 2006; Rutter 2006). Decades of research have identified numerous risk and protective factors that are statistically associated with poor child adaptation, development, and psychopathology, "not because they represent a risk process as such, but because they predispose to other experiences that actually mediate the risk" (Rutter 1999, p. 120). As an example, Rutter describes the loss of a parent through divorce, separation, or death in which most of the risk derives from the family discord and conflict that precedes and follows family breakup, and from the associated difficulties in parenting, rather than the broken home as such. Parental loss predicts a broad range of child difficulties and thus serves as a general "marker of risk." However, the negative "chain reaction" of dysfunctional family processes that parental loss precipitates or exacerbates are more proximal causes (and predictors) of children's difficulties. Further, knowledge regarding specific disrupted family processes that mediate the links between causal risk factors and adverse outcomes is typically much more helpful in devising effective family interventions than focusing exclusively on the precipitating risk factor, such as divorce per se (Layne et al. 2010). Luthar's influential 50-year review of the resilience literature (2006) concludes with two salient recommendations for further study and application: First, given the long and growing list of protective and vulnerability factors identified as modifiers of high risk circumstances, there is a practical need to prioritize which ones are most important. Considerations should thus focus on which are most influential, which will result in sustained benefits for children, and which are amenable to change. From this strategic point of view, there is broad consensus that family factors are at the top of the list given that they constitute the most proximal determinants of child adjustment, are often malleable, and promote enduring changes for the child (Luthar and Zelazo 2003). Current efforts in resilience research should thus focus on unpacking the contributions of distinct protective or risk-enhancing family processes as they operate within natural contexts (Layne et al. 2007, 2009; Masten 2001). Such efforts will enhance the accuracy of risk screening methods and the development of more focused, efficient interventions that are based not only on clear goals concerning what need(s) to be achieved, but also on clear guiding theory regarding specific risk mechanisms, protective mechanisms, and mechanisms of therapeutic change (Rutter 1999, 2006).

The study of military families carries considerable promise for the development of models of mechanisms of familial risk and resilience. In comparison with other highly stressful or traumatogenic experiences impacting children and families such as natural disasters, war, or community violence, wartime deployment is typically a predictable and protracted stressor that involves a large and diverse population. These features of deployment create opportunities for the systematic study of its effects on families and for large-scale program development and evaluation (Skodol et al. 1996). Responding to the urgent need to develop and evaluate resilience-enhancing interventions for military families undergoing deployment also creates an opportunity to create "state-of-the-art" practices. These practices should be guided by accurate formulations of risk and resilience-including key family processes linked to enhanced resilience and positive outcomes for children and family members exposed to stressful or traumatic circumstances (Cicchetti and Hinshaw 2002; Luthar 2006). A sizeable and growing literature describing 
potential risk mechanisms associated with wartime deployment will facilitate these efforts, including the effects of psychological and physical injury of the deployed parent on spouses, children, and family functioning (Chandra et al. 2011; Galovski and Lyons 2004; Lester et al. 2010; McFarlane 2009; Palmer 2008).

\section{Mechanisms of Risk for Military Families}

Converging clinical and epidemiological research has identified five interrelated sets of family processes theorized to serve as risk mechanisms for families exposed to stressful circumstances, and that appears amenable to change via relatively brief intervention (Lester et al. 2011a; Luthar 2006; Riley et al. 2008; Walsh 2006). Table 1 presents the risk mechanisms and their theorized proximal outcomes.

Incomplete Understanding of the Impact

of Deployment and Combat Operational Stress, and Inaccurate Developmental Expectations

Large numbers of returning service members and their spouses experience distress and clinically significant levels of depression and anxiety (Eaton et al. 2008). On mandatory post-deployment surveys, $18 \%$ of all returning service members, including parents and non-parents, report significant mental health problems (Hoge et at. 2006). ${ }^{1}$ In smaller-scale studies of service members who are parents, as many as 39 and $32 \%$, respectively, of returned parents and their non-military spouses report clinically significant symptoms of distress, primarily in the form of anxiety and depression (Lester et al. 2010). These distress reactions may alter parental functioning at home. For example, parents with depressive symptoms may be excessively tired, disengaged, irritable, and perceived by their children as distant and uncaring, or by spouses as "lazy and unmotivated" (Beardslee 2002; Cummings et al. 2001). Further, parents with even subclinical levels of post-traumatic stress may have difficulty tolerating normal household stressors, reacting with anger or aggression or by psychologically or physically distancing themselves from family activities and consistent, nurturing interactions that foster secure child attachment and marital quality (Galovski and Lyons 2004; Sherman et al. 2005). A lack of awareness regarding the nature and impact of stress or a specific disorder, or the fact that a parent or spouse is suffering from a

\footnotetext{
${ }^{1}$ Generally, the deployment cycle is considered to include the following phases: pre-deployment, deployment, reintegration (during the initial month of the service member's return), and post-deployment (extending up to a year after the service member's return).
}

psychological condition, may lead family members to become confused, frustrated, or to inappropriately blame themselves when a trauma or loss reminder evokes an abrupt shift in emotions, or withdrawal from family activities by a parent or spouse (Layne et al. 2006). These changes can undermine feelings of trust and closeness within the family and hobble critical supportive processes (Beardslee et al. 2007; Riley et al. 2008; Walsh 2006).

Although living with a depressed, highly anxious, or traumatized parent may always be difficult, some evidence suggests that helping family members understand the nature and cause of the parent's condition, and the ways in which that condition is often expressed, can help family members cope with it more effectively (Beardslee et al. 2003; Wyman et al. 2000). Recent evidence indicates that a spouse's perception and understanding of a service member's combat exposure and reasons for functional difficulties have a significant bearing on marital satisfaction (Renshaw et al. 2008). When armed with appropriate information, spouses were able to be more flexible, to make allowances for a husband or wife's problematic behavior, and to do so with lower levels of personal distress (Renshaw 2008). In studies of families in which a parent suffered from depression, a similar salutary effect emerged when information regarding depression was provided in combination with an opportunity for the family to discuss these issues (Beardslee et al. 1998). Children and adolescents were aided by the knowledge that neither their parent's condition nor related family problems were their fault; further, family members were generally better able to adjust and develop better coping and problem-solving strategies (Beardslee 2002; Wyman et al. 2000).

Similarly, returning service members may become frustrated and angry with a spouse who, despite not having directly experienced combat or deployment, is nevertheless functioning poorly due in part to symptoms of vicarious post-traumatic stress, depression, sleep problems, or anxiety (Renshaw et al. 2008). Without adequate information concerning the prevalence of spousal distress and impaired functioning during and after deployment, the service member may not understand and support the spouseactions that may have serious consequences for the marriage and the family (Renshaw 2008; Solomon et al. 1992).

The fact that children of different ages and temperaments often exhibit very different reactions to the absence and return of a parent, may give rise to parental misunderstandings during reintegration (Lester et al. 2011a). For example, younger children may not recognize a parent who has been absent for months or may experience developmental regressions in the form of separation anxiety or the inability to sleep alone, whereas teens may exhibit sullen or defiant behavior. Without an understanding of these expected reactions, parents may become excessively 
Table 1 Risks and likely outcomes in families affected by wartime deployment/parental combat operational stress, which are addressed by the FOCUS program

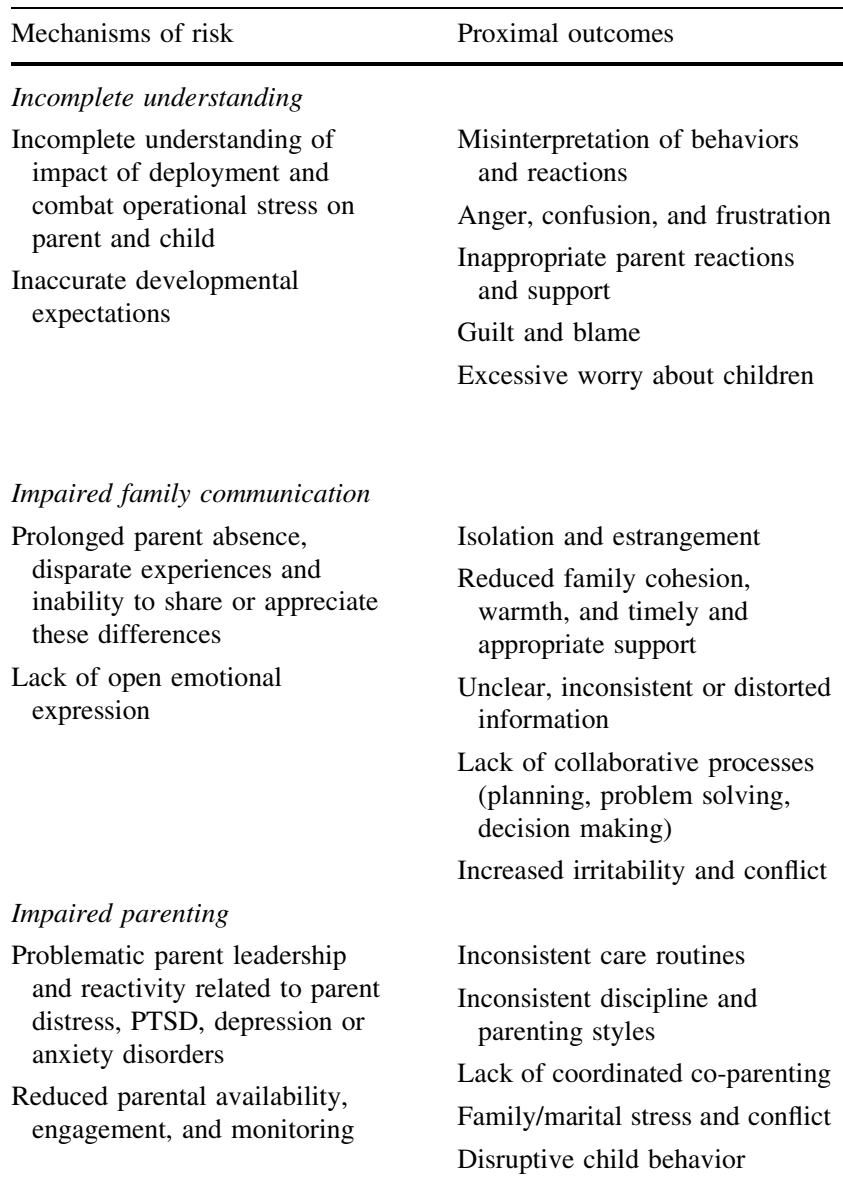

Impaired family communication

disparate experiences and inability to share or appreciate hese differences

ack of open emotional expression

\section{Impaired family organization}

Overly rigid or chaotic structure that is easily disrupted under stress

\section{Lack of guiding belief systems}

Lack of framework to provide coherence and make meaning out of adversity

Lack of shared beliefs to support family identity, optimism, and to mobilize coping efforts

Lack of access to supportive community, rituals, and transcendent values
Rigid or chaotic parenting styles

Poorly defined boundaries, roles, and responsibilities

Erratic care routines

Disengagement of family members

Decreased cohesion, confidence and optimism

Feelings of isolation, hopelessness and pessimism

Loss of sense of coherence (life as being comprehensible, manageable and meaningful)

Lack of common family mission and "esprit de corps"

Program components

Expected outcomes

Psychoeducation

Developmental guidance

Proactive family planning for deployment

Positive reframing of problem and goal statements

Train on managing trauma/loss reminders

Highlight family strengths

Share individual narratives/cocreation of shared family narrative

Perspective taking

Process distortions and misattributions

Communication skills training

Family meetings

Parent narrative sharing and processing of differences and misunderstandings

Parent leadership training

Development of shared goals and support of co-parenting

Skill training in collaborative decision making, problem solving, goal setting, reminder management, emotional regulation

Shared parent narratives to support effective co-parenting

Activities and assignments to enhance family structure and closeness

Training on collaborative family skills and maintaining care routines

Crisis contingency planning

Family narrative creation to increase coherence and make sense of experiences

Normalize and contextualize adverse experiences

Highlight strengths and past successes to support optimism

Reframe negative interpretations

Support family's religious or spiritual inclinations
Increased understanding, flexibility, and support

Forgiveness of self and others

Accurate expectations and parental support

Increased family confidence and optimism

Decreased isolation and estrangement

Clear and emotionally open communication

Increased family cohesion, warmth, and timely and appropriate support

Increased sense of coherence and meaning

Effective and coordinated parenting

Increased parental availability and monitoring

Improved care routines

Increased parental perceived competence

Flexible family structure able to adjust to stress and change

Well-defined family boundaries, roles, responsibilities and care routines

Effective co-parenting

Development of family mission and goals, and support for shared beliefs

Increased sense of coherence and meaning related to current adversities

Increased access to family, military, community, and spiritual resources and services 
worried, feel guilty, or over-react to changes that may be developmentally appropriate and are usually transient (Rosenheck 1986). This theorized risk mechanism carries clear implications for intervention. For example, providing information regarding child development and developmentally linked reactions to stressful circumstances can calm parents' misplaced fears, help them to identify child reactions or issues that warrant concern, and provide young or inexperienced parents with guidance concerning the levels of monitoring, autonomy, structure, and disciplinary reactivity that are most helpful for children of different ages (Lester et al. 2011b; Saltzman et al. 2009a).

\section{Impaired Family Communication}

A second mechanism through which wartime deployment and combat operational stress can adversely affect family functioning is through breakdowns in family communication. Many circumstances, both during and after deployment, may undermine family communication and members' ability to rebuild closeness after each deployment separation. Repeated prolonged separations that create marked discrepancies in individual family members' experiences or that cause the deployed member to miss important developmental milestones can create a gulf between the returning parent and the family that requires significant time and effort to bridge (Lester et al. 2011b; MacDonald et al. 1999). Factors that may lead to impaired communication during the reintegration period include emotional numbing or avoidance in the service member secondary to post-traumatic stress or depression and unwillingness to talk about wartime experiences, including (often legitimate) concerns about exposing family members to violent or graphic contents, fears of being negatively judged, or the need to protect mission-related information (Lincoln et al. 2008; Riggs et al. 1998). Withholding strong emotions, pain, fear, and worry may also stem from a military family culture that enjoins members to "tough it out" and not burden others with expressions of need or hurt (Hall 2008) or the belief among some military families that it is easier for spouses to lead emotionally parallel lives as long as repeated deployments allow the servicemember parent to pass through the home as an occasional "visitor" (Zoroya 2009).

Multiple studies document that serious consequences for marital and family relations follow when emotional estrangement and communication are not successfully bridged after deployments (Beym and Lange 1974; Matsakis 1996). For example, spouses of traumatized veterans report feeling alienated by veterans' emotional withdrawal (Rosenheck and Thomson 1986), and there is an elevated risk for depression among both spouses if they feel unable to confide in each other (Haley 1985). Further, it is particularly difficult for veterans to resume the roles of parent and spouse when they are unable to communicate and positively engage with their spouse and family members (Matsakis 1996; Riggs et al. 1998). The breakdown of open and emotionally resonant communication across the family frequently impairs essential sharing and parental monitoring of children's daily experiences and activities, accomplishments, and concerns, and undercuts the family's ability to provide timely and appropriate support (Cozza et al. 2005; Sherman et al. 2005). A hallmark of impaired communication is a diminished sense of family closeness, warmth, and support—each a vital family resilienceenhancing process (Walsh 2006, 2007).

\section{Impaired Parenting Practices}

In the resilience literature, supportive and responsive parenting is the single most robust general protective factor for children exposed to various adversities (Luthar 2006; Luthar and Zelazo 2003). It is also true that breakdowns in parenting practices and the parent-child relationshipchild abuse and maltreatment being extreme examplesrepresent one of the most pernicious risk factors for negative child outcomes (Cicchetti and Valentino 2006). As noted previously, a third or more of military parents experience significant distress, often in the form of depression, anxiety, or sleep disturbances (Lester et al. 2011b). These forms of distress tend to be more prevalent among caregiving spouses during deployment, although they may also persist during the reintegration period (Mansfield et al. 2010). Researchers have documented a cascade of negative life events for the service member whose combat-related stress and post-traumatic symptoms may affect sleep patterns, mood, arousal level, irritability, and ability to tolerate daily domestic transactions, and for the spouse who may be similarly symptomatic or hyperreactive due to the "pile up" of stressors experienced on the "home front" over extended and multiple deployments (Galovski and Lyons 2004; Lester et al. 2010, 2011a; Sherman et al. 2005). In both cases, the common final pathway frequently involves decreases in parental engagement and associated thoughtful, skilled, and consistent parenting responses. Recent studies have also confirmed the relationship between parental deployment and rates of child maltreatment and neglect involving the athome caregiving spouse (Gibbs et al. 2007; Rentz et al. 2007). In most cases, child maltreatment or neglect act as a broad indicator or end-product of multiple deficits or breakdowns in parenting practices, which may include shortfalls in parental availability and monitoring, inconsistent or coercive discipline, inadequate or developmentally inappropriate care routines, and child exposure to marital conflict or domestic violence (Dishion and Patterson 2006). 
Studies have also identified specific parenting practices that are corrosive to family resilience. These practices include overly rigid or authoritarian parenting styles, in which rules and roles are inflexibly maintained, often with significant power differentials between husband and wife and a lack of mutual respect or coordinated actions (Walsh 2006). Coercive forms of parenting in which parents focus on children's misbehavior with harsh consequences while leaving positive efforts or successes unrewarded are also associated with diminished child and family resilience (Patterson 2002). A recent review of risk and resilience factors for military families concluded that the stressful effects of military life on child outcomes (including frequent relocation, parental deployment, and parental PTSD) are largely mediated by the quality of the parent-child relationship and interactions. Of particular note, parental attitudes and adjustment, quality of the parent-child attachment, and the presence of parenting and coping skills constitute proximal variables that were better predictors of child outcomes than the frequency or severity of the stressor event (Palmer 2008). The literature on family transactions involving depressed parents may provide a useful window for illuminating influential mechanisms of risk transmission. For example, families with a depressed parent are frequently characterized by a chain of events in which the parent, due to lethargy or preoccupation, is unable to maintain consistent child discipline and daily household routines for sleeping, eating, and self-care (Riley et al. 2008). Such disruptions in parenting practices can, over time, undermine children's ability or willingness to regulate emotion and behavior, leading to social withdrawal or disruptive behavior when confronted with stressors. Such behavior may prompt varied parental responses and escalating cycles of conflict, withdrawal, and disengagement in the home (Burkem 2003; Cummings et al. 2001).

\section{Impaired Family Organization}

In her distillation of processes theorized to support family resilience, Walsh (2006) gives high priority to specific organizational characteristics. Specifically, resilient families tend to develop a flexible structure that balances strong leadership and the ability to maintain continuity in the face of adversity, alongside the adaptive capacity to accommodate to change (Kelley et al. 1994). For example, it is essential to maintain consistent and reliable care routines within the family for sustained positive child adjustment, even during highly stressful or disruptive family experiences (Ahrons 2004; Imber-Black et al. 2003). At the same time, the family should be able to adapt to new circumstances introduced by both expectable stressors, such as child development and parental deployment, as well as unexpected changes, such as parental injury and impairment (Olson and Gorell 2003).

In contrast, overly rigid or chaotic families that provide either too much or too little structure may undermine family resilience (Walsh 2006, 2007). Excessively rigid families insist on maintaining a prescribed set of rules and roles and have difficulty adjusting to the changes required during deployment, reunion, and reintegration. Under stress, rigid families may become even more inflexible, authoritarian, and intolerant of deviations, whereas parental leadership in chaotic families can be erratic, with shifting roles, response styles, and family routines. Stressful circumstances can increase these tendencies and cause the family to slip toward disorganization and lack of control (Walsh 2006).

\section{Lack of Guiding Belief Systems}

Studies of families living in Belfast who were forced to contend with the sustained hardships associated with the long-term civil unrest in Northern Ireland found that children from families who held strong beliefs regarding the value and importance of the struggle had better long-term outcomes than those from families who were less ideologically committed (Shaw 2003). In a similar manner, recent studies of families with one or more parents involved in OEF/OIF have found that family belief in the mission was a strong predictor of better coping and adaptation among the children (Palmer 2008). These findings are consistent with the understanding that resilience derives substantially from the family's ability to make sense of an experience and endow it with meaning (Antonovsky 1998; Patterson and Garwick 1994), a capacity that derives from adherence to a common set of beliefs or transcendent values.

Almost by definition, trauma, loss, and major life changes create a crisis of meaning and can threaten systems of belief and personal identity. As noted by Bruner (1986) and Walsh (2006), this tension prompts the construction or reorganization of a collective life story and set of beliefs. Conversely, without a viable belief system to help them make sense of current adversities and confer meaning to daily struggles and sacrifices, the individual may become lost to bitter internal ramblings that lead to cynicism and doubt - conditions that are corrosive to individual and family resilience. Families who must endure hardship and privation without the shelter or galvanizing support of a shared sense of mission can become less organized and less able to work together in a hopeful and coordinated fashion. In such circumstances, individual family members may feel isolated and overall levels of family cohesion and support may decline (Antonovsky and Sourani 1988; McNulty 2010; Walsh 2006). 


\section{Mechanisms of Resilience Enhancement in Military Families}

Just as stress and adversity can initiate negative chain reactions within families that undermine resilient adjustment, positive chain reactions, referred to as "resource gain cycles" (Layne et al. 2009), can be strategically set in motion to enhance individual and family resilience (see also Rutter 1999). In this section, we describe family interventions theorized to enhance familial resilience by catalyzing adaptive family processes. These interventions comprise the central features of the FOCUS Program and are outlined in the "Program Interventions" column of Table 1, accompanied by a description of targeted outcomes.

Providing Psychoeducation and Developmental Guidance

In providing a family with pragmatically detailed information about the impact of deployment and parental distress on individual family members and family functioning, a number of positive family processes may be initiated that can interrupt the cycle of negative family events prompted by deficits in knowledge or incomplete forms of understanding. When family members are helped to acknowledge the range, severity, and duration of stressors they have encountered, they can justifiably back away from feelings of shame or self-recrimination about their current struggles or perceived weaknesses. When they are provided with current information which shows that even service members and spouses who have not experienced direct combat or life threat may still develop debilitating forms of anxiety, depression, and vicarious forms of traumatic stress, that there is a high prevalence of these conditions, and that there are things they can do to get better, then they may be able to openly explore how their changing mental health status has changed them as spouses and parents and engage in proactive healing efforts (Lester et al. 2010, 2011a). Most importantly, when children are helped to understand that a distressed parent's anger or inappropriate reactions are not due to anything that the child has done, then they are freer to engage in productive forms of self-care and problem solving with other family members (Beardslee and Knitzer 2003). Parents able to distinguish between developmentally normative and problematic reactions to stress and change exhibited by their children may be able to worry less and provide more helpful and well-received forms of support and guidance. Armed with this kind of information that is applied to the particular circumstances and needs of a family and pitched so that it can be heard and understood by all of its' members, family processes may be initiated, which will help to move them toward feeling more in control, optimistic, and confident (Saltzman et al.

2009a, b).

\section{Developing Shared Family Narratives}

After one or more wartime deployments, a gulf of time, disparate experiences, and problematic interpretations often span between a service member and his or her family. Bridging this gulf and re-establishing familiarity and closeness is a central challenge during the extended reintegration period (Palmer 2008; Sherman et al. 2005). Unfortunately, there are numerous factors including parent distress, psychopathology, lack of communication skills, and constraining family or cultural strictures, which may interfere with this process. By providing a family with a structured and safe forum for individual family members to share their experiences, reactions, fears, and ongoing concerns, and to then collectively craft a family narrative, a number of critical family processes and capabilities can be brought online in service of improved adaptation and resilience. These are described briefly later.

\section{Enhancing Family Awareness and Understanding}

When a family member constructs a personal narrative of his/her experiences across deployments, progress is made in organizing and making sense of the events (Antonovsky 1998; Cohler 1991). When individual narratives are shared and an encompassing family narrative is co-constructed, there is an opportunity to jointly acknowledge the family's history of multiple challenges and successes, to normalize and contextualize individual experiences or reactions that may have previously been viewed with shame or derision, to soften judgment with understanding, and to develop a sense of coherence about these shared experiences (Saltzman et al. $2009 \mathrm{a}, \mathrm{b})$. Coherence is defined here as a global orientation to life as comprehensible, manageable, and meaningful (Walsh 2006).

\section{Improving Family Empathy and Communication}

When narrative sharing is structured so that individual family members feel safe to express their personal feelings and reactions, and those listening are enjoined to listen in a compassionate manner, the level of family empathy may be increased as members learn to take the perspective of the other and appreciate previously unvoiced differences in experience and perception. Family members are also provided a means to safely overcome obstacles to communication, which may include cultural or family prohibitions against burdening others with expressions of strong feelings or needs, symptoms of emotional numbing, avoidance 
and withdrawal related to depression or traumatic stress, or reticence on the part of service members to talk about extreme experiences. For the latter circumstance, service members can be coached to share their reactions without focusing on upsetting or graphic details.

\section{Fostering Confidence and Hope}

In facilitating the construction and sharing of individual members' narratives, the counselor can highlight personal and family assets and strengths while underscoring past successes in dealing with similar challenges. The counselor can also identify problematic misattributions or distortions as family members process the different experiences and perceptions contained in their individual narratives. This may include calling upon family members to challenge or clarify problematic attributions, such as a circumstance in which one family member feels inappropriately responsible for a negative outcome or misconstrues the actions of another family member.

\section{Supporting Open and Effective Communication}

A key hallmark of a healthy family is direct, clear, consistent, and honest communication, and the capacity to tolerate open expression of emotion (Walsh 2003, 2006). These characteristics are especially important for families experiencing stress and change, given that unclear, distorted, or vague communication can rob family members of the essential tools for successfully adapting to change and challenges. Moreover, when parents withhold or "put a happy face" on communications about serious or difficult issues, they leave blanks that children fill in, often with their worst imaginings. The importance of open emotional expression within the family is underscored by findings that strong emotions that are not permitted expression can "go underground" and emerge in a destructive fashion through emotional, behavioral, and even somatic symptoms (Greene et al. 2003). For example, in trying to explain why her deployed husband would be returning a month later than expected, a military mother minimized the situation and simply said he had "unfinished work in Iraq." The children could sense her tension and began to think that their father had been injured or even killed. In a similar fashion, a husband and wife felt uncomfortable speaking to their 8-year-old son about the father's injury, and the series of reconstructive surgeries and long course of rehabilitation required for his recovery. Feeling like he could not ask questions about his father's health, the son believed that his father was very fragile and could die at any time. $\mathrm{He}$ avoided their usual roughhousing because he thought it would hurt his father; each time the father went to the hospital for a procedure, the son feared that his father would not come back. Denied an avenue to express or clarify his fears, the son's suppressed distress showed up in uncharacteristic emotional outbursts and behavioral problems.

All families have their own culture, complete with implicit and explicit rules for communication and behavior. To a great extent, parents establish family rules and the family climate, although cultural and ethnic differences account for important differences in the ways family communicate emotions (McGoldrick et al. 2005). As such, it is important to work within the personal and cultural framework of each family and help them to find appropriate ways to invite sharing of a wide range of feelings and through mutual empathy extend a tolerance for differences and the expression of strong emotions (Bowen 1978; Walsh 2006).

\section{Enhancing Selected Family Resiliency Skills}

Specific parent skill sets and family-level coping strategies can help families anticipate, plan for and mitigate the impact of stressful events, and improve child adjustment (Saltzman et al. 2009a, b; Spoth et al. 2002). Randomized controlled trials of resilience-enhancing family programs have identified specific parent- and family-level skills as being effective in improving child outcomes over time (Beardslee et al. 2007; Layne et al. 2008). These core skills include stress management and emotion regulation, collaborative goal setting and problem solving, and managing trauma and loss reminders.

Although normally applied to individuals, stress management and emotion regulation skills can be effectively leveraged at the family level to enhance resilience. For example, family members can be trained to collectively identify and anticipate stressful situations, monitor idiosyncratic expressions of distress among different family members, poll individual family members for desired forms of support, and to provide appropriate types of support in a timely and developmentally appropriate manner. Families may be coached to develop a shared vocabulary and method for checking in with one another's emotional or stress status, and to practice using a specific set of coping strategies including relaxation, distraction, activity planning, cognitive reframing, and positive messaging to assist each other in modulating family stress and reactivity (Lester et al. 2010, 2011a; Saltzman et al. 2009a, b). Families can also profit from training in collaborative goal setting and problem solving. Families impacted by ongoing stress and impaired parenting may be disorganized and lack proactive strategies for managing problems or including family members in decision making and planning (Beavers and Hampson 2003; Ryan et al. 2005). The result can be a chaotic or rigidly closed family structure in which 
individual members feel isolated, marginalized, and out of control. Establishing a collaborative and explicit process by which family members may jointly voice preferences and develop coordinated plans of action can increase a sense of connectedness and control. Training in these collaborative family-level skills that invite joint participation and shared decision making can also generalize to other areas of family functioning and increase the family's adaptive and resilient potential (Walsh 2006). Managing combat and deployment stress reminders can be an essential skill for families in which members are reactive to cues that remind them of highly stressful or traumatic experiences. Research has delineated separate classes of reminders related to specific trauma experiences (e.g. the backfire of a car, hot and dry weather, or uncontrolled crowds at malls and stores - all potential reminders that may evoke stressful memories of combat or danger) and to loss experiences (e.g. specific times, activities, or settings, which remind an individual of the absence of a deceased loved one or the traumatic circumstances of the death) (Layne et al. 2007, 2010). These cues may evoke such reactions as abrupt mood shifts, withdrawal, or shifts in behavior that are confusing and disruptive to family relations. Such cues may contribute to family disengagement and conflict and may undermine supportive familial transactions. In addition to education about the impact of reminders, parents and children are taught to identify personal- and family-level triggers and to develop collaborative strategies for modulating their impact (Layne et al. 2006, 2008; Pynoos et al. 1999).

\section{Supporting Effective and Coordinated Parent Leadership}

Building on the military model designed to maximize "unit cohesion" and support, parents should be supported to provide clear and consistent leadership for their family unit. As noted previously, parental distress and psychopathology may result in impaired forms of parenting that lead to reduced parental availability, limited engagement and monitoring, inconsistent care routines and discipline, increased stress and conflict across the family, and, in many cases, disruptive or problematic child behavior. Various tools may promote consistent and coordinated parental leadership in accordance with a co-parenting model. Co-parenting refers to a set of values and practices that lead to a co-equal and mutually supportive approach to parenting. In order to effectively co-parent, parents must learn to communicate clearly with each other, support each other, and collaboratively negotiate childrearing decisions and disagreements, along with family roles and duties (Feinberg 2002). A large body of research suggests that the capacity for co-parenting and power-sharing has important implications for both child and family outcomes (Feinberg and Kan 2008). In sharing personal narratives of deployment experiences, parents can increase their understanding of what each other went through during difficult times and come to better appreciate the others' current reactions and difficulties. By helping couples and parents frame problems in an interactive fashion such that blaming is reduced and mutual contributions to current problems and potential solutions are highlighted, spouses are better able to craft collaborative goals that provide a road map for working together (Long and Young 2007). Further, by developing relational means of regulating distressing emotions and reactions and an ongoing means of checking in with each other for course adjustments, parents can learn to help each other navigate the shifting terrain of childrearing during a time of war (Gewirtz et al. 2008).

The FOCUS Program: A Family-Centered ResilienceEnhancing Program

\section{Program Development}

The FOCUS Program (Families OverComing Under Stress) is one of the first trauma-informed, skill-based preventive interventions that has been designed expressly for families (Saltzman et al. 2007, 2009b). Based upon initial meetings in 2002 of the UCLA-Harvard development team, the conceptual model for the intervention was mapped out, drawing upon the team's prior family-focused programs that had been stringently evaluated through randomized controlled trials (Beardslee et al. 2003; Layne et al. 2008; Rotheram-Borus et al. 2006). The source programs were developed to aid children and families contending with war and community violence (UCLA Trauma Grief Program), parental human immunodeficiency virus (HIV) infection (Project Talk), and parental depression (Project Family Talk). Randomized controlled trials with longitudinal follow-up were conducted for each of the source programs with sustained positive outcomes for each including sustained reductions in posttraumatic stress disorder, depression and maladaptive grief among warexposed youth (Layne et al. 2008; Saltzman et al. 2001, 2002), improved overall adjustment of children of HIVpositive parents with more employment, greater school attendance, and reduced childbearing (Lester et al. 2008), and in families with depressed parents, an improvement in child-coping skills and family communication, closeness, and supportiveness (Beardslee et al. 2003, 2007).

Core elements of each program were incorporated into a streamlined model that could be applied to a range of challenging child and family circumstances. In the terms of current prevention models (National Research Council and Institute of Medicine 2009), the FOCUS Program is 
positioned as a "selected" (secondary) and "indicated" (tertiary) prevention. ${ }^{2}$ As described elsewhere (Saltzman et al. 2009a, b), over the next 4 years, the program was implemented as an "enhanced service" by FEMA in communities across Florida impacted by multiple hurricane, it was used in a California children's hospital to serve families contending with child medical trauma, and was adapted and implemented via a Robert Woods Johnson grant for first responders (police, fire, and emergency medical personnel) in New Orleans following Hurricane Katrina. Starting in 2006, the program was adapted for military families through consultation and piloting with the US Navy and Marine Corps with support from the Fredrick R Weisman Philanthropic Foundation, and then in 2008, selected as a large-scale demonstration project by the US Navy Bureau of Medicine and Surgery (Lester et al. 2010, 2011a). During this period, the FOCUS Program also integrated key aspects of Navy and Marine's prevention and resilience framework called the Stress Continuum Model. This is a destigmatizing heuristic for recognizing significant but preclinical levels of distress and functional impairment in service members and their spouses and children, and Combat and Operational Stress First Aid that is a widely disseminated preventive intervention (Nash 2011).

Throughout its various adaptations and applications, the FOCUS Program has maintained the same structure and central elements. It offers family psychoeducation, structured communication and narrative sharing experiences, and the development of specific family-level skills, with the intent of improving child and family outcomes by enhancing key family resilience processes. The family resilience processes targeted by the program are the five described in the previous section. It should also be noted that the randomized controlled trials conducted with the three source programs were all conducted with culturally and ethnically diverse populations. Outcomes with regard to program effectiveness indicate that these interventions have utility for children and families from diverse backgrounds. Furthermore, the program was adapted to a broadly diverse military culture through piloting and consultation with multicultural families and ongoing refinement over the course of a 3-year, large-scale demonstration project with military families across the US and Japan (Beardslee et al., in press).

To support the FOCUS Program's rapid dissemination and uptake across diverse military settings and cultures, a number of innovative strategies were employed to integrate

\footnotetext{
2 The IOM model divides the continuum of care into three parts: prevention, treatment, and maintenance. The prevention category is divided into three classifications-universal, selective and indicated prevention interventions, which replace the concepts of primary, secondary, and tertiary prevention.
}

the program into existing systems of care and reduce obstacles to help seeking. First, program offices and dedicated staff were conveniently located on base and away from customary mental health service delivery sites. This was part of a comprehensive effort to design and frame the program as a strength-based, skills training intervention for families, as opposed to "therapy" for individuals with mental health problems. As such, service providers were identified as "Resiliency Trainers" rather than therapists; a substantive distinction maintained by the programs' focus and design. Second, the program was embedded within the military system of care via strong endorsement from command, active outreach and partnerships with medical and mental health providers on and off base, and with chaplains, and family service programs and school staff at each installation. And third, the FOCUS staff was welloriented to military culture through explicit training and efforts to recruit clinicians who were ex-military or spouses of service members (Lester et al. 2011a; Beardslee et al., in press).

\section{Description of Program}

The FOCUS family resilience-enhancing program is designed for culturally diverse, single and dual parent families contending with challenges encountered during pre-deployment, deployment, reintegration, and long-term post-deployment. The program is described as offering "selected" preventive services as it is used for families exposed to significant levels of stress or loss who may be at risk for psychological disturbance or impaired adaptation; and as offering "indicated" preventive services for families and family members who may already present with significant psychological or behavioral impairment. The program, which is administered by trained clinicians, is designed to reduce the likelihood of problematic outcomes for families and family members who are "at risk" due to stress, trauma or loss, and to support the recovery of symptomatic family members by mobilizing supportive and resilience-enhancing processes within the family. For families in which a family member presents with significant psychological disturbance, referrals for more intensive forms of treatment are provided that may be enlisted concurrently with the FOCUS Program.

The intervention is generally delivered over six to eight sessions: the first two with the parents, the second two with the children, a fifth session with the parents to prepare for the family sessions, and then a series of one to three family sessions. The program is very flexible, however, and the number of actual meetings can be increased or decreased according to the needs, capacities, and availability of the family. Special adaptations of the program have also been 
developed for families with preschool-aged children (Mogil et al. 2010) for families with a wounded, injured, or ill parent, and for couples without children. All are being piloted at selected installations (Fig. 1).

During the initial parent sessions, parents fill out a series of selected assessments on a networked laptop computer that provides instantaneous scoring and feedback to the Resiliency Trainer on the parent and family status with regard to parental deployment and loss experiences, parental post-traumatic stress, depression, anxiety, traumatic grief, family functioning, and current difficulties and relative strengths of each child. Feedback is provided via color-coded flags with specific recommendations for the Trainer and the family. The parents are then helped to describe their current concerns, challenges, and wishes for their family. The Resiliency Trainer incorporates the assessment feedback and the parents' input to frame initial goals for the family's participation in the program, recognizing that some family needs may be beyond the scope of the FOCUS preventive program, in which case additional service referrals are provided. From the very beginning and throughout the program, psychoeducation on the impact of deployment and any assessed psychological difficulties is woven into the discussions along with developmental guidance with regard to the current needs and difficulties experienced by the children. The parents are then led through a structured narrative process in which they individually share their experiences with each other across key periods. This includes events before, during, and after deployments and, frequently, high stress or formative experiences at prior stages of their relationship or family history. Such events may include relocations, family deaths, illnesses, injuries, or other potentially traumatic events that may present opportunities for misunderstanding or estrangement between the parents.
A unique aspect of this process pioneered in the FOCUS program is the use of a timeline to graphically render family members' narrative in a way that makes it easy to note differences in individual experiences and attributions. An example is provided below in which the narrative timelines for both parents are superimposed. Prior to constructing their narratives, parents are trained to use the "feeling thermometer" (shown on the left side of the timeline) as a means to describe levels of distress: higher levels on the thermometer denote higher levels of distress. The thermometer on the vertical axis of the timeline, then, provides a means to calibrate elevations on the personal timeline so that more stressful experiences are shown as elevations and less stressful experiences are shown as points lower down (Fig. 2).

For the example family, the mother was invited to share her narrative first and draw her timeline on a large piece of poster paper with the assistance of the Resiliency Trainer. Her husband was coached to listen supportively with the understanding that he would soon have his own chance to share his story. Following a number of intrusions, he was reminded that his silent support of her telling her story did not indicate agreement and that it is normal for all couples to have very different experiences and interpretations of the same events. After the mother completed her narrative with a brief summarization by the Trainer, the husband was invited to share his narrative, drawing his timeline in a different color. While both husband and wife shared their narratives and drew their timelines, the Trainer notated the timelines, sometimes with verbatim statements made by the parents with regard to their thoughts and feelings attendant to the events described. After both timelines were completed, the Trainer summarized commonalities and points of divergence in the narratives and then led a discussion in which the parents identified "new information"
Fig. 1 FOCUS: individual family training

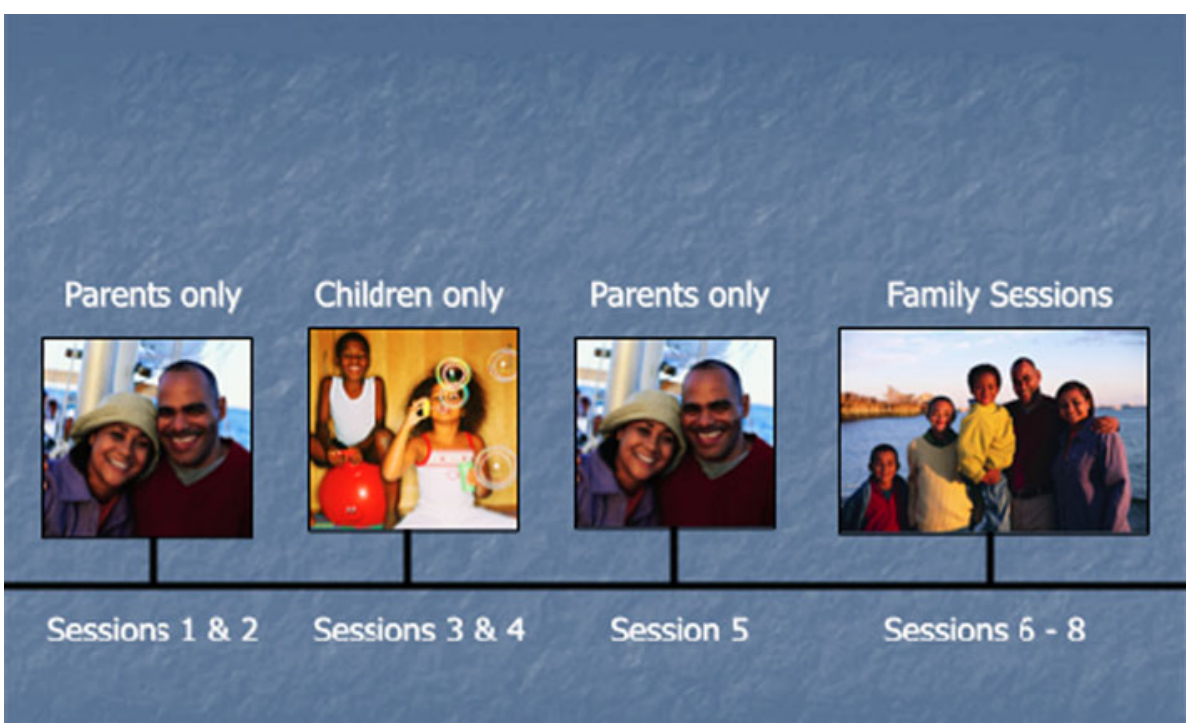


Fig. 2 Parental timeline

\section{Parental Timeline}

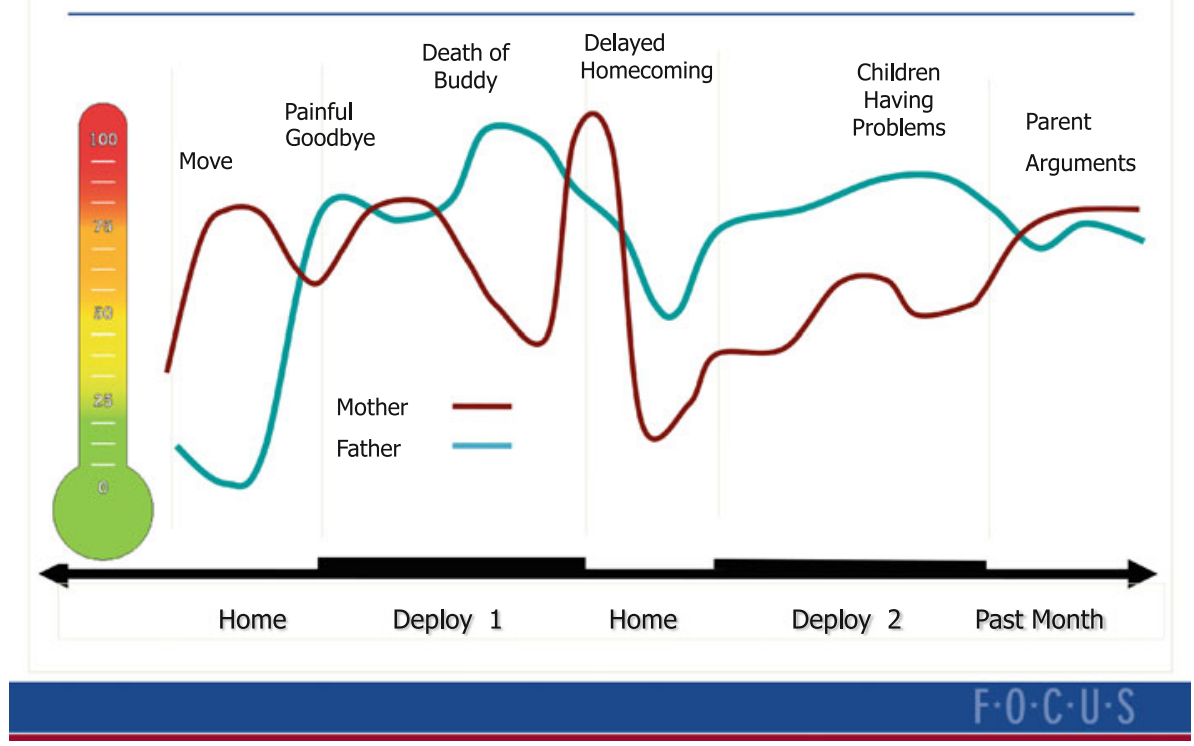

or insights gleaned from hearing their partners' experiences and perceptions and processed differences in interpretation and attributions that may contribute to current tension or relational distance.

In the example, the husband noted that he was unaware that his wife was so distressed over their move of duty station prior to his first deployment, though he reminded himself that this move involved leaving her family and close friends. He was aware that she was greatly angered by his decision to stay beyond his expected return date resulting in a delayed homecoming from his first deployment. He was not aware, however, of the fact that breakdowns in communication resulted in his wife and children having a few days in which they thought his delay was related to his possible injury or death. Similarly, his wife was surprised that her husband believed their 12-year-old son hated him because during the goodbyes for his first deployment, his son would not look at him or speak to him. She also did not know that phone and email reports from her during his second deployment of the children having serious academic and behavioral problems left him feeling helpless and extremely depressed.

The type of misunderstandings and simple omissions of personal information characterized in the example are frequently at the heart of family estrangements and breakdowns in relationships. In processing these differences, parents are able to exercise their empathic muscles and develop a platform for greater mutual understanding, tolerance, and collaboration. It also helps to clear the way for working together more effectively in the program and map out shared family goals.
The set of child sessions involve meetings with the children to cover some of the same ground as that accomplished with the parents: orient them to the program, collect assessment data, elicit current concerns and wishes, begin developmentally appropriate psychoeducation, and elicit personal narratives. Depending on the age of the children, they may do a similar timeline as the parents or, for younger children, a "timemap" that is structured more like a gameboard with spaces for the child to draw or describe important events and experiences. In the current example, the 12-year-old boy talked about being so upset at his father's leavetaking for his first deployment that he would not look at him for fear he would break down and cry. He also spoke about being very sad because even after his father returned from his first deployment, he was so distracted and irritable that the son felt that he did not want to be around him. His 10-year-old sister spoke about becoming increasingly worried about her father being killed during the second deployment and angry at her mother who seemed very stressed and "bossy" and complained constantly to her about money problems. During their individual sessions, the Trainer was able to gain the children's agreement to share their timelines in the family sessions, and the list of specific questions they had for their parents which included: "why do you fight so much?", "are you going to get divorced?", "are we going to have to move because we have no money?", etc.

To insure that the family sessions go well and that the parents are able to play an effective leadership role, a separate meeting is held with them to review key portions of the children's timelines and questions. This provides an 
opportunity to insure that the parents can respond in a measured and effective manner to even volatile or sensitive issues and to select which portions of their narratives are appropriate for their children to hear. Sometimes more than one session is required to model and practice the requisite skills.

The first family session is devoted to sharing family narratives and addressing differences in experiences and interpretations across the family. This session usually has the children sharing their timelines or timemaps with the parents invited to share their experiences or clarify misunderstandings or misattributions. In the current example, the father was relieved and actually touched to hear that his son avoided him when he said goodbye because he was so upset and afraid that he would disappoint his dad if he cried. The father also took this opportunity to explain to his son that he was distant and irritable when he returned, not because of anything the son did, but because he was still struggling with memories of what happened to him down range and the loss of one of his buddies. During this session and the next one, the family worked through all of the important issues, omissions, and misunderstandings, and the parents were able to answer the childrens' questions in an honest yet hopeful manner. This cleared the deck for the final sessions that were devoted to practicing selected family-level skills which, for this family, included collaborative goal setting, problem solving, scheduling fun time together, checking in with each other, and developing individual and family-level strategies for dealing with stressors and expected trauma and loss reminders for the father.

\section{Summary of Program Outcomes}

We now briefly summarize key findings of an evaluation study of the FOCUS Program based on pre-, post- and follow-up data collected during the first 20 months of its operation at eleven military installations in the US and Japan. Detailed outcome data are presented elsewhere (Lester et al., in press). These findings are then discussed relative to the proposed model of risk and resilienceenhancing family mechanisms.

The evaluation study focused on 488 Navy and Marine families (parents $=742$, children $=873$ ) who participated in the program at baseline. Most families had an active duty (AD) parent and a non-active duty (NAD) parent and had experienced an average of 4.51 deployments $(\mathrm{SD}=4.78)$ since the birth of the family's first child. Family members filled out a series of standardized measures of psychological health and coping including, for parents, a measure of post-traumatic stress symptoms, a measure of depression and anxiety, and a measure of family adjustment; and for children, a measure of psychological adjustment with subscales for conduct problems, emotional symptoms, total difficulties, as well as a subscale for pro-social behavior, and a measure of coping strategies in use.

The results indicated that, at baseline, the parents were significantly higher on all forms of psychological distress (posttraumatic stress, depression, and anxiety) than community norms, and the children were higher than community norms for emotional and behavioral problems. Pre-post change scores showed significant improvements across all measures for the parents, with the percentage of parents with clinically meaningful impairments due to anxiety going from $20 \%$ to approximately $7 \%$ post-intervention; in depression from approximately $25-8 \%$; and in perceptions of unhealthy family functioning from over $50 \%$ to approximately $30 \%$. The percentage of children with clinically meaningful impairment in conduct problems went from almost 50 to $28 \%$ post-intervention, in emotional symptoms from 40 to $22 \%$, and in total difficulties from 44 to $21 \%$. There were also significant pre-post intervention improvements in child pro-social functioning and increases in childrens' use of positive coping strategies.

Of particular relevance to the current article are the findings that improvements in specific aspects of family functioning including communication, affective responsiveness and involvement, role clarity, and problem solving, all characteristics linked to the core family resilient processes, were associated with reductions in parent and child distress and improvements in their adaptive functioning overall. This supports the central hypothesis that family resilient processes can be changed via a brief family-centered intervention and that these changes are linked to improved child outcomes.

\section{Conclusion}

An understanding of specific risk and resilient processes within military families is of special importance at the current time given the ongoing stress and trauma burdens laid on them through multiple wartime deployments and parental injury and psychological illness. The mechanisms of risk detailed in this article provide a road map of common tendencies by which military families may become distressed and impaired from a resilience perspective. The mechanisms of resilience provide a blueprint for brief, family-centered interventions designed to jump-start or enhance resilient functioning of military families. The FOCUS Program has used that blueprint to develop a program that specifically targets family resilience-enhancing processes in service of the improved adaptation of parent and child during and after times of stress. Based on the initial outcome data, it appears that the program is 
successfully serving these families in the manner proscribed. And while these findings are heartening, more rigorous and controlled research is necessary to further clarify the hypothesized model-linking family processes and child and parent adaptation. Two randomized controlled trials of the program are currently in progress to provide that clarification and expand the program's evidence base. One is a multisite study of an adaptation of the program for combat-injured service members and their families who are being served at Walter Reed, Brooke, and Madigan Army Medical Centers. This is being conducted by the Center for the Study of Traumatic Stress at the Uniformed Services University. A second randomized controlled study is being planned in partnership with the West Los Angeles Veteran's Administration Medical Center. In order to make clear the causal relationships between changes in resilient family processes and child and parent adaptation and functioning, a structural equation modeling study of the FOCUS outcome data is currently being completed and will be published shortly.

A large part of the learning curve for the rapid dissemination of the FOCUS Project has involved the development of a working relationship between University and military partners, the identification and use of a set of core preventive interventions, and the use of innovative technologies including web-based management and assessment tools that supported a coordinated implementation of the program with a high degree of fidelity at distal sites, and continuous quality improvement and rapid integration of lessons from the field (Beardslee et al., in press). Future implementations will focus on making the FOCUS Program available to a broader military and a non-military population. An example of the former is an ongoing project with the Los Angeles County Department of Mental Health to train their clinicians to provide FOCUS services to veterans, including National Guard and Reserve service members and their families. An example of the latter is the current plans to make FOCUS available in community mental health and medical settings. Controlled studies along with field implementations of FOCUS in diverse settings will continue to throw light on the mechanisms of risk and resilience in families and deepen our understanding of the "active ingredients" in family-centered interventions. This work should be designed to clarify the specific ways in which family culture and ethnicity may help to support resilience and recovery. Most importantly, refinements in resilience theory, prevention science, and strategies for implementation must be applied to a scalable dissemination of family-centered services to populations that are most exposed to trauma and loss. At this point in our national history, this includes military families, and we must use the emerging tools and technologies to insure that longterm distress, disability, and impaired development do not have to be the cost of serving one's country.
Open Access This article is distributed under the terms of the Creative Commons Attribution Noncommercial License which permits any noncommercial use, distribution, and reproduction in any medium, provided the original author(s) and source are credited.

\section{References}

Ahrons, C. (2004). We're still family. New York: Harper Collins.

Anthony, E. J. (1974). The syndrome of the psychologically invulnerable child. In E. J. Anthony \& C. Koupernik (Eds.), The child in his family: Children at psychiatric risk (Vol. 3, pp. 3-10). New York: Wiley.

Antonovsky, A. (1998). The sense of coherence: An historical and future perspective. In H. McCubbin, E. Thompson, A. Thompson, \& J. Fromer (Eds.), Stress, coping, and health in families: Sense of coherence and resiliency (pp. 3-20). Thousand Oaks, CA: Sage.

Antonovsky, A., \& Sourani, T. (1988). Family sense of coherence and family adaptation. Journal of Marriage and the Family, 50, 89-92.

Beardslee, W. R. (2002). Out of the darkened room: Protecting the children and strengthening the family when a parent is depressed (1st ed.). Boston: Little, Brown and Company.

Beardslee, W. R., Gladstone, T. R. G., Wright, E. J., \& Cooper, A. B. (2003). A family-based approach to the prevention of depressive symptoms in children at risk: Evidence of parental and child change. Pediatrics, 112(2), 119-131.

Beardslee, W. R., \& Knitzer, J. (2003). Strengths-based family mental health services: A family systems approach. In K. Maton, C. Schellenbach, B. Leadbeater, \& A. Solarz (Eds.), Investing in children, youth, families, and communities: Strengths-based research and policy (pp. 157-171). Washington, DC: America Psychological Association.

Beardslee, W.R., Lester, P., Klosinski, L., Saltzman, W.R., Woodward, K., Nash, W., et al. (in press). Family-centered preventive intervention for military families: Implications for implementation science. Prevention Science.

Beardslee, W. R., Versage, E. M., \& Gladstone, T. R. (1998). Children of affectively ill parents: A review of the past 10 years. Journal of the American Academy of Child and Adolescent Psychiatry, 37, 1134-1141.

Beardslee, W. R., Wright, E. J., Gladstone, T. R. G., \& Forbes, P. (2007). Long-term effects from a randomized trial of two public health preventive interventions for parental depression. Journal of Family Psychology, 21(4), 703-713.

Beavers, W. R., \& Hampson, R. B. (2003). Measuring family competence: The beavers systems model. In F. Walsh (Ed.), Normal family processes (3rd ed., pp. 549-580). New York: Guilford Press.

Beym, D., \& Lange, J. (1974). Waiting wives: Women under stress. American Journal of Psychiatry, 131, 283-286.

Bowen, M. (1978). Family therapy in clinical practice. New York: Jason Aronson.

Brody, G. (2004). Siblings' direct and indirect contributions to child development. Current Directions in Psychological Science, 13, 124-126.

Bruner, J. (1986). Actual minds, possible worlds. Cambridge, MA: Harvard University Press.

Burkem, L. (2003). The impact of maternal depression on familial relationships. International Review of Psychiatry, 15(3), 243-255.

Chandra, A., Burns, R., Tanielian, T., \& Jaycox, L. (2011). Understanding the deployment experience for children and youth from military families. In Wadsworth \& MacDermid (Eds.), Risk and 
resilience in US military families (pp. 175-192). New York, NY: Springer Science \& Business Media.

Chandra, A., Sandraluz, L. C., Jaycox, L. H., Tanielian, T., Burns, R., Ruder, T., et al. (2010). Children on the homefront: The experience of children from military families. Pediatrics, 125(1), $16-25$.

Cicchetti, D., \& Hinshaw, S. (2002). Development and psychopathology: Editorial: Prevention and intervention science: Contributions to developmental theory. Development and Psychopathology, 14(4), 667-671.

Cicchetti, D., \& Valentino, K. (2006). An ecological-transactional perspective on child maltreatment: Failure of the average expectable environment and its influence on child development. In D. Cicchetti \& D. Cohen (Eds.), Developmental psychopathology, Vol 3: Risk, disorder, and adaptation (2nd ed.). Hoboken, NJ: Wiley.

Cohler, B. (1991). The life story and the study of resilience and response to adversity. Journal of Narrative and Life History, 1, 169-200.

Cozza, S., Chun, R. S., \& Polo, J. A. (2005). Military families and children during operation Iraqi Freedom. Psychiatric Quarterly, 76(4), 371-378.

Cummings, E. M., DeArth-Pendley, G., DuRocher-Schudlich, T., \& Smith, D. A. (2001). Parental depression and family functioning: Towards a process-oriented model of children's adjustment. In S. R. Beach (Ed.), Marital and family processes in depression: A scientific foundation for clinical practice (pp. 89-110). Washington, DC: American Psychological Association.

Dishion, T. J., \& Patterson, G. R. (2006). The development and ecology of antisocial behavior in children and adolescents. In D. Cicchetti \& D. J. Cohen (Eds.), Developmental psychopathology, Vol 3: Risk, disorder, and adaptation (2nd ed., pp. 503-541). Hoboken, NJ: Wiley.

Eaton, K. M., Hoge, C. W., Messer, S. C., Whitt, A. A., Cabrera, O. A., McGurk, D., et al. (2008). Prevalence of mental health problems, treatment need, and barriers to care among primary care-seeking spouses of military service members involved in Iraq and Afghanistan deployments. Military Medicine, 173(11), $1051-1056$.

Feinberg, M. E. (2002). Coparenting and the transition to parenthood: A framework for prevention. Clinical Child and Family Psychology Review, 5, 173-195.

Feinberg, M. E., \& Kan, M. L. (2008). Establishing family foundations: Intervention effects on coparenting, parent/infant well-being, and parent-child relations. Journal of Family Psychology, 22, 253-263.

Flake, E. M., Davis, B. E., Johnson, P. L., \& Middleton, L. S. (2009). The psychosocial effects of deployment on military children. Journal of Developmental and Behavioral Pediatrics, 30(4), 271-278.

Forgatch, M. S., \& Ogden, T. (2006). Enhancing resilience in a nationwide system of care for children with behavior disorders. In S. Neumar (Chair), Developing resilience and strength across the life span. Paper presented at the fourth world conference on the promotion of mental health and prevention of mental and behavioral disorders, enhancing resilience, Oslo, Norway.

Galovski, T. E., \& Lyons, J. (2004). The psychological sequelae of exposure to combat violence: A review of the impact on the veteran's family. Aggression and Violent Behavior: A Review Journal, 9, 477-501.

Garmezy, N. (1974). The study of competence in children at risk for severe psychopathology. In E. J. Anthony \& C. Koupernik (Eds.), The child in his family: Children at psychiatric risk (Vol. 3). New York: Wiley.

Garmezy, N. (1987). Stress, competence, and development: Continuities in the study of schizophrenic adults, children vulnerable to psychopathology, and the search for stress-resistant children. American Journal of Orthopsychiatry, 57, 159-174.

Garmezy, N., \& Masten, A. (1986). Stress, competence, and resilience: Common frontiers for therapist and psychopathologist. Behavior Therapy, 17, 500-521.

Gewirtz, A., Forgatch, M., \& Wieling, E. (2008). Parenting practices as potential mechanisms for child adjustment following mass trauma. Journal of Marital and Family Therapy, 34(2), 177-192.

Gibbs, D. A., Martin, S. L., Kupper, L. L., \& Johnson, R. E. (2007). Child maltreatment in enlisted soldiers' families during combatrelated deployments. Journal of the American Medical Association, 298, 528-535.

Greene, S. M., Anderson, E., Hetherington, E. M., Forgatch, M. S., \& DeGarmo, D. S. (2003). Risk and resilience after divorce. In F. Walsh (Ed.), Normal family processes (pp. 96-120). New York, NY: The Guilford Press.

Haley, S. A. (1985). Some of my best friends are dead: Treatment of the PTSD patient and his family. Family Systems Medicine, 3(1), $17-26$.

Hall, L. K. (2008). Counseling military families: What mental health professionals need to know. New York, NY: Routledge/Taylor and Francis Group.

Hauser, S. T. (1999). Understanding resilient outcomes: Adolescent lives across time and generations. Journal of Research on Adolescence, 9(1), 1-24.

Hoge, C. W., Auchterlonie, J. L., \& Milliken, C. S. (2006). Mental health problems, use of mental health services, and attrition from military service after returning from deployment to Iraq or Afghanistan. Journal of the American Medical Association, 295(9), 1023-1032.

Imber-Black, E., Roberts, J., \& Whting, R. (Eds.). (2003). Rituals in families and family therapy (2nd ed.). New York: Norton.

Kelley, M., Herzog-Simmer, P., \& Harris, M. (1994). Effects of militaryinduced separation on the parenting stress and family functioning of deploying mothers. Women in the Navy, 6, 125-138.

Layne, C. M., Beck, C. J., Rimmasch, H., Southwick, J. S., Moreno, M. A., \& Hobfoll, S. E. (2009). Promoting "resilient" posttraumatic adjustment in childhood and beyond: "Unpacking" life events, adjustment trajectories, resources, and interventions. In D. Brom, R. Pat-Horenczyk, \& J. Ford (Eds.), Treating traumatized children: Risk, resilience, and recovery (pp. 13-47). New York: Routledge.

Layne, C. M., Olsen, J. A., Baker, A., Legerski, J. P., Isakson, B., Pašalić, A., et al. (2010). Unpacking trauma exposure risk factors and differential pathways of influence: Predicting post-war mental distress in bosnian adolescents. Child Development, 81, 1053-1075.

Layne, C. M., Saltzman, W. R., Poppleton, L., Burlingame, G. M., Pašalić, A., Duraković-Belko, E., et al. (2008). Effectiveness of a school-based group psychotherapy program for war-exposed adolescents: A randomized controlled trial. Journal of the American Academy of Child and Adolescent Psychiatry, 47, $1048-1062$.

Layne, C. M., Warren, J. S., Saltzman, W. R., Fulton, J. B., Steinberg, A. M., \& Pynoos, R. S. (2006). Contextual influences on posttraumatic adjustment: Retraumatization and the roles of revictimization, posttraumatic adversities, and distressing reminders. In A. L. Schein, H. I. Spitz, G. M. Burlingame, P. R. Muskin, \& S. Vargo (Eds.), Psychological effects of catastrophic disasters: Group approaches to treatment (pp. 235-286). New York, NY: Haworth Press.

Layne, C. M., Warren, J., Watson, P., \& Shalev, A. (2007). Risk, vulnerability, resistance, and resilience: Towards an integrative conceptualization of posttraumatic adaptation. In M. M. Friedman, T. M. Keane, \& P. A. Resick (Eds.), Handbook of PTSD: Science and practice (pp. 497-520). New York: Guilford. 
Lester, P., Leskin, G., Woodward, K., Saltzman, W., Nash, W., Mogil, C., et al. (2011a). Wartime deployment and military children: Applying prevention science to enhance family resilience. In S. M. Wadsworth \& D. Riggs (Eds.), Risk and resilience in US military families. New York, NY: Springer.

Lester, P., Mogil, C., Saltzman, W., Woodward, K., Nash, W., Leskin, G., et al. (2011b). FOCUS (families overcoming under stress): Implementing family-centered prevention for military families facing wartime deployments and combat operational stress. Military Medicine, 176(1), 19-25.

Lester, P., Peterson, K., Reeves, J., Knauss, L., Glover, D., Mogil, C., et al. (2010). The long war and parental combat deployment: Effects on military children and at-home spouses. Journal of the American Academy of Child and Adolescent Psychiatry, 49(4), 310-320.

Lester, P., Rotheram-Borus, M. J., Elia, C., Elkavich, A., \& Rice, E. (2008). TALK: Teens and adults learning to communicate. In C. W. LeCroy (Ed.), Evidence-based treatment manuals for children and adolescents (pp. 170-285). New York, NY: Oxford University Press.

Lester, P., Saltzman, W. R., Woodward, K., Glover, D., Leskin, G. A., Bursch, B., et al. (in press). Evaluation of a Family Centered Prevention Intervention for Military Children and Families Facing Wartime Deployments. American Journal of Public Health.

Lincoln, A., Swift, E., \& Shorteno-Fraser, M. (2008). Psychological adjustment and treatment of children and families with parents deployed in military combat. Journal of Clinical Psychology, 64, 984-992.

Long, L., \& Young, M. (2007). Counseling and Therapy for Couples. Belmont, CA: Brooks/Cole Cengage Learning.

Luthar, S. S. (2006). Resilience in development: A synthesis of research across five decades. In D. Cicchetti \& D. J. Cohen (Eds.), Developmental psychopathology: Risk, disorder, and adaptation (pp. 740-795). New York: Wiley.

Luthar, S. S., \& Cicchetti, D. (2000). The construct of resilience: Implications for interventions and social policies. Development and Psychopathology, 12, 857-885.

Luthar, S., Doyle, K., Suchman, N., \& Mayes, L. (2001). Developmental themes in women's emotional experiences of motherhood. Development and Psychopathology, 13(1), $165-182$.

Luthar, S., \& Zelazo, L. B. (2003). Research on resilience: An integrative review. In S. S. Luthar (Ed.), Resilience and vulnerability: Adaptation in the context of childhood adversities (pp. 510-549). New York: Cambridge University Press.

MacDonald, C., Chamberlain, K., Long, N., \& Flett, R. (1999). Posttraumatic stress disorder and interpersonal functioning in Vietnam War veterans: A meditational model. Journal of Traumatic Stress, 12(4), 701-707.

Mansfield, A., Kaufman, J., Marshall, S., Gahynes, B., Morrissey, J., \& Engel, C. (2010). Deployment and the use of mental health services among US army wives. The New England Journal of Medicine, 362, 101-109.

Masten, A. (2001). Ordinary magic: Resilience processes in development. American Psychologist, 56, 227-238.

Masten, A. S., Best, K. M., \& Garmezy, N. (1990). Resilience and development: Contributions from the study of children who overcome adversity. Development and Psychopathology, 2, 425-444.

Matsakis, A. (1996). Vietnam wives: Facing the challenges of life with veterans suffering post-traumatic stress (2nd ed.). Baltimore, MD: The Sidran Press.

McFarlane, A. C. (2009). Military deployment: the impact on children and family adjustment and the need for care. Current Opinion in Psychiatry, 22(4), 369-373.
McGoldrick, M., Giordano, J., \& Garcia-Preto, N. (Eds.). (2005). Ethnicity and family therapy (3rd ed.). New York: Guilford Press.

McNulty, P. A. F. (2010). Adaptability and resiliency of military families during reunification: Initial results of a longitudinal study. Federal Practitioner, March, 18-27.

Mogil, C., Paley, B., Doud, T., Havens, T., Moore-Tyson, J., Beardslee, W., et al. (2010, September). Zero to Three, pp. 10-16.

Nash, W. P. (2011). US Marine Corps and Navy combat and operational stress continuum model: A tool for leaders. In E. C. Ritchie (Ed.), Operational behavioral health. Washington, DC: Borden Institute Textbook of Military Psychiatry.

National Research Council and Institute of Medicine. (2009). Preventing mental, emotional, and behavioral disorders among young people: Progress and possibilities. committee on prevention of mental disorders and substance abuse among children, youth, and young adults: Research advances and promising interventions. In M. O’Connell, T. Boat, \& K. E. Warner (Eds.), Board on children, youth, and families, division of behavioral and social sciences and education. Washington, DC: The National Academies Press.

Olson, D. H., \& Gorell, D. M. (2003). Circumplex model of marital and family systems. In F. Walsh (Ed.), Normal family processes (3rd ed., pp. 514-548). New York: Guilford Press.

Palmer, C. (2008). A theory of risk and resilience factors in military families. Military Psychology, 20, 205-217.

Patterson, J. M. (2002). Integrating family resilience and family stress theory. Journal of Marriage and the Family, 64, 349-360.

Patterson, J. M., \& Garwick, A. W. (1994). Levels of family meaning in family stress theory. Family Process, 33, 287-304.

Pynoos, R., Steinberg, A., \& Piacentini, J. (1999). A developmental psychopathology model of childhood traumatic stress and intersection with anxiety disorders. Biological Psychiatry, 46(11), 1542-1554.

Renshaw, K. D. (2008, July). Psychological and marital functioning in spouses of National Guard/Reserve service members deployed during OEF/OIF: The importance of spouses' perceptions, research symposium on military families. Military Family Research Institute at Purdue University and the Center for deployment Psychology, Purdue University, West Lafayette, IN.

Renshaw, K. D., Rodriques, C. S., \& Jones, D. H. (2008). Psychological symptoms and marital satisfaction in spouses of Operation Iraqi Freedom veterans: Relationships with spouses' perceptions of veterans' experiences and symptoms. Journal of Family Psychology, 22(3), 586-594.

Rentz, E. D., Marshall, S. W., Loomis, D., Casteel, C., Martin, S. L., \& Gibbs, D. A. (2007). Effects of deployment on the occurrence of child maltreatment in military and nonmilitary families. American Journal of Epidemiology, 165, 1199-1206.

Riggs, D. S., Byrne, C. A., Weathers, F. W., \& Litz, B. T. (1998). The quality of the intimate relationships of male Vietnam veterans: Problems associated with posttraumatic stress disorder. Journal of Traumatic Stress, 11, 87-101.

Riley, A. W., Valdez, C. R., Barrueco, S., Mills, C., Beardslee, W., Sandler, I., et al. (2008). The development of a family-based program to reduce risk and promote resilience among families affected by maternal depression: Theoretical basis and program description. Clinical Child and Family Psychology Review, 11, $12-29$.

Rosenheck, R. (1986). Impact of posttraumatic stress disorder of World War II on the next generation. Journal of Nervous and Mental Disease, 174(6), 319-327.

Rosenheck, R., \& Thomson, J. (1986). Detoxification of Vietnam war trauma: A combined family-individual approach. Family Process, 25(4), 559-570. 
Rotheram-Borus, M. J., Stein, J. A., \& Lester, P. (2006). Adolescent adjustment over six years in HIV-affected families. Journal of Adolescent Health, 39(2), 174-182.

Ruscio, A. M., Weathers, F. W., King, L. A., \& King, D. W. (2002). Predicting male war-zone veterans' relationships with their children: The unique contribution of emotional numbing. Journal of Traumatic Stress, 15, 351-357.

Rutter, M. (1979). Protective factors in children's responses to stress and disadvantage. In M. W. Kent \& J. E. Rolf (Eds.), Primary prevention in psychopathology: Social competence in children (Vol. 8, pp. 49-74). Hanover, NH: University Press of New England.

Rutter, M. (1999). Resilience concepts and findings: Implications for family therapy. Journal of Family Therapy, 21(2), 119-144.

Rutter, M. (2006). Promotion of resilience in the face of adversity. In A. Clarke Stewart \& J. Dunn (Eds.), Families count: Effects on child and adolescent development (pp. 26-52). New York, NY: Cambridge University Press.

Ryan, C., Epstein, N. B., Keitner, G., Miller, I. W., \& Bishop, D. S. (2005). Evaluation and treating families: The McMaster approach. New York: Routledge.

Saltzman, W. R., Babayan, T., Lester, P., Beardslee, W. R., \& Pynoos, R. S. (2009a). Family-based treatment for child traumatic stress: A review and report on current innovations. In D. Brom, R. Pat-Horenczyk, \& J. D. Ford (Eds.), Treating traumatized children: Risk, resilience and recovery (pp. 240-254). New York, NY: Routledge/Taylor and Francis Group.

Saltzman, W. R., Layne, C. M., Steinberg, A. M., Arslanagic, B., \& Pynoos, R. S. (2002). Developing a culturally-ecologically sound intervention program for youth exposed to war and terrorism. Child and Child Psychiatric Clinics of North America, 12, 319-342.

Saltzman, W. R., Lester, P., Beardslee, W., \& Pynoos, R. (2007). FOCUS for military families: Individual family resiliency training manual (1st Ed.). Unpublished manual, UCLA.

Saltzman, W. R., Lester, P., Pynoos R., Mogil C., Green, S., Layne C. M., et al. (2009b). FOCUS for military families: Individual family resiliency training manual (2nd Ed.). Unpublished manual, UCLA.

Saltzman, W. R., Pynoos, R. S., Layne, C. M., Aisenberg, E., \& Steinberg, A. M. (2001). Trauma- and grief-focused intervention for adolescents exposed to community violence: Results of a school-based screening and group treatment protocol. Group Dynamics: Theory, Research, and Practice, 5(4), 291-303.

Shaw, J. A. (2003). Children exposed to war/terrorism. Clinical Child and Family Psychology Review, 6(4), 237-246.

Sherman, M. D., Zanotti, D. K., \& Jones, D. E. (2005). Key elements in couples therapy with veterans with combat-related posttraumatic stress disorder. Professional Psychology: Research and Practice, 36(6), 626-633.

Skodol, A. E., Schwartz, S., Dohrenwend, B. P., Levav, I., et al. (1996). PTSD symptoms and comorbid mental disorders in Israeli war veterans. British Journal of Psychiatry, 169(6), 717-725.

Solomon, Z., Waysman, M., Levy, G., Fried, B., Mikulincer, M., Benbenishty, R., et al. (1992). From front line to home front: A study of secondary traumatization. Family Process, 31, 289-302.

Spoth, R. L., Kavanagh, K., \& Dishion, T. (2002). Family-centered preventive intervention science: Toward benefits to larger populations of children, youth, and families. Prevention Science, $3,145-152$.

Walsh, F. (2003). Family resilience: A framework for clinical practice. Family Process, 42(1), 1-18.

Walsh, F. (2006). Strengthening family resilience (2nd ed.). New York: Guilford Press.

Walsh, F. (2007). Traumatic loss and major disasters: Strengthening family and community resilience. Family Process, 46(2), 207-227.

Werner, E. E. (1993). Risk, resilience, and recovery: Perspectives from the Kauai longitudinal study. Development and Psychopathology, 5, 503-515.

Werner, E., \& Smith, R. (2001). Journeys from childhood to midlife: Risk, resilience, and recovery. Ithaca, NY: Cornell University Press.

Wesphal, R. J., \& Woodward, K. R. (2010). Family fitness. Military Medicine, 175, 97-102.

Wyman, P. A., Sandler, I. N., Wolchik, S. A., \& Nelson, K. (2000). Resilience as cumulative competence promotion and stress protection: Theory and intervention. In D. Cicchetti, J. Rappaport, I. Sandler, \& R. P. Weissberg (Eds.), The promotion of wellness in children and adolescents (pp. 133-184). Washington, DC: CWLA Press.

Zoroya, G. (2009, August 5). Broken Families. USA Today. p. A1. 